\title{
Crosstalk Between Mucosal Inflammation and Bone Metabolism in Chronic Rhinosinusitis
}

\author{
Roza Khalmuratova ${ }^{1}$ (i) $\cdot$ Hyun-Woo Shin ${ }^{1,2,3,4,5}$ (i) \\ ${ }^{l}$ Obstructive Upper airway Research (OUaR) Laboratory, Department of Pharmacology, Seoul National University College of Medicine, Seoul; \\ ${ }^{2}$ Department of Biomedical Sciences, Seoul National University Graduate School, Seoul; ${ }^{3}$ Ischemic/Hypoxic Disease Institute and ${ }^{4}$ Cancer \\ Research Institute, Seoul National University College of Medicine, Seoul; ${ }^{5}$ Department of Otorhinolaryngology-Head and Neck Surgery, \\ Seoul National University Hospital, Seoul, Korea
}

Chronic rhinosinusitis (CRS) is a multifactorial and highly heterogeneous upper airway disease that affects approximately $12 \%$ of the general population. There is increasing evidence supporting the impact of osteitis on the pathophysiology of CRS. Osteitis is frequently observed in patients with CRS, and is associated with severe sinonasal inflammation and recalcitrant cases. The overlying inflammatory sinonasal mucosa plays a critical role in the initiation of osteitis; however, the underlying molecular mechanisms and functional significance remain unclear. Increasingly many studies have suggested that immune cells play a crucial role in the bone remodeling process in CRS. The purpose of this review is to summarize the current state of knowledge regarding the specific role of sinonasal inflammation in bone remodeling in CRS patients.

Keywords. Osteitis; Chronic Rhinosinusitis; Inflammation; Osteoblasts; Osteoclasts; Cytokine

\section{INTRODUCTION}

Chronic rhinosinusitis (CRS) is a multifactorial and highly heterogeneous upper airway disease that affects approximately $12 \%$ of the general population [1-4]. CRS also significantly affects the quality of life of individuals with the disease. CRS is classified into two major subtypes based upon its phenotypic manifestation: CRS without nasal polyps (CRSsNP) and CRS with nasal polyps (CRSwNP) [5]. The inflammatory patterns of CRSsNP and CRSwNP are known to be different. CRSsNP is predominantly characterized by neutrophilic inflammation with increased levels of T helper (Th) 1 cytokines [1,6]. CRSwNP is often characterized by eosinophilia, immunoglobulin E production, and Th2 cytokine expression in Western countries [7]. In

\footnotetext{
- Received March 21, 2020

Revised June 8, 2020

Accepted June 8, 2020

- Corresponding author: Hyun-Woo Shin

Department of Pharmacology, Seoul National University College of

Medicine and Department of Otorhinolaryngology-Head and Neck Surgery,

Seoul National University Hospital, 103 Daehak-ro, Jongno-gu,

Seoul 03080, Korea

Tel: +82-2-740-8285, Fax: +82-2-745-7996

E-mail: charlie@snu.ac.kr
}

contrast, only approximately half of patients with CRSwNP in Asian countries demonstrate eosinophilic inflammation with Th2 cells [8-10]. Non-eosinophilic CRSwNP commonly demonstrates Th1/Th17-predominant immune responses [11].

Increasing evidence supports the impact of osteitis on the pathophysiology of CRS [12]. Osteitis is often observed in CRS patients, and is associated with disease severity and recalcitrant cases [13]. Osteitis is defined as the process of new bone formation and bone remodeling inside the paranasal sinuses, and is characterized by periosteal thickening, new woven bone formation, bone resorption, and fibrosis $[14,15]$. However, the causes and pathogenesis of osteitis in CRS remain incompletely understood. The purpose of this review is to summarize the current state of knowledge regarding the specific role of sinonasal inflammation in bone remodeling in CRS patients.

\section{INCIDENCE OF OSTEITIS}

The exact prevalence and incidence of osteitis vary depending on the evaluation criteria. Osteitis was identified in $39.6 \%$ of CRS patients who underwent primary surgery [16]. Lee et al. [15] reported the presence of osteitis in $36 \%-53 \%$ of CRS pa-

Copyright @ 2021 by Korean Society of Otorhinolaryngology-Head and Neck Surgery

This is an open-access article distributed under the terms of the Creative Commons Attribution Non-Commercial License (https://creativecommons.org/licenses/by-nc/4.0)

which permits unrestricted non-commercial use, distribution, and reproduction in any medium, provided the original work is properly cited. 
tients based on either the radiographic criterion of bony thickening or pathologic findings. Snidvongs et al. [17] found evidence of osteitis in around $51 \%$ of CRS patients, with a higher prevalence in patients with prior sinus surgery (76\%). Georgalas et al. [18] reported that 33\% of primary CRS patients showed signs of osteitis. Bony changes were present in $75 \%$ of patients who underwent prior sinus surgery [18].

\section{DIAGNOSTIC METHODS}

Histology is considered to be the most precise method of diagnosing osteitis, and several grading systems for osteitis have been proposed [19-21]. The histologic indicators of osteitis include periosteal thickening, increased activity of osteoblasts and osteoclasts, woven bone formation, and fibrosis [14]. Although histology provides an accurate way to diagnose osteitis, radiological studies are the most generally used investigations. Computed tomography (CT) is currently the imaging modality of choice for evaluating CRS due to its superior detail for imaging bone and its excellent sensitivity and specificity with regard to detecting periosteal thickening. CT scans were first used by Biedlingmaier et al. [20] to diagnose osteitis, and CT findings were found to be correlated with histologic findings in patients with advanced-grade disease. Cho et al. [19] demonstrated radiologic and histopathologic evidence of bony changes in CRS patients. Furthermore, Lee et al. [15] measured the thickness of bony partitions in the maxillary, ethmoid, and sphenoid sinuses to determine the severity and radiologic evidence of osteitis. Georgalas et al. [18] proposed the Global Osteitis Scoring Scale (GOSS), which generates an aggregate score depending on bony thickness and the pattern of bony involvement in each sinus. The GOSS score was found to be correlated with the LundMackay score, duration of symptoms, and prior surgery.

\section{DISEASE SEVERITY AND OUTCOMES}

Osteitis has been demonstrated to be associated with disease severity. Previous studies documented higher overall CT scores in patients with osteitis than in those without osteitis [15,22]. A number of factors had significantly higher prevalence in patients

\section{H I}

- Increasing evidence supports the impact of osteitis on the pathophysiology of chronic rhinosinusitis.

- The overlying inflammatory sinonasal mucosa plays a critical role in the initiation of osteitis.

- Osteitis has been demonstrated to be associated with disease severity. with osteitis, including nasal polyps, a history of prior surgery, increased mucosal inflammation, and worse treatment outcomes $[22,23]$. The ethmoid sinus was the predominant site of osteitis in eosinophilic CRSwNP, whereas non-eosinophilic CRSwNP showed maxillary predominance based on CT findings [24,25].

\section{BONE CELLS}

Bone remodeling is the process by which mature bone is continually removed by resorption and new bone is formed [26]. Osteoblasts play a dominant role in this process and also control osteoclast activity via the release of soluble mediators $[27,28]$. Ishino et al. [29] established an osteoblast cell model from the ethmoid sinus from patients with CRS, in which they were able to culture and differentiate cells from explanted sinus bone that expressed extracellular matrix proteins. Stevens et al. [30] found a fundamental phenotypic difference in adhesion and mineralization between osteoblasts from patients with CRS and osteoblasts from controls. These findings suggest that identifying the immunological and molecular mechanisms of osteoblast activation can be used to better elucidate the bone remodeling process in an inflamed microenvironment. Further studies are needed to explore possible causal links between overlying mucosal inflammation and adjacent bone structures since bone cells play a central role in the bone remodeling process.

\section{PATHOPHYSIOLOGY AND MOLECULAR MECHANISMS}

\section{Eosinophilic remodeling}

The overlying inflammatory sinonasal mucosa plays a critical role in the initiation of osteitis; however, the molecular mechanisms and functional significance remain unclear. Increasingly many studies have suggested that immune cells are crucial for bone remodeling in CRS patients. Snidvongs et al. [17] found that osteitis was associated with tissue and serum eosinophilia in both patients with and without prior surgery. Mehta et al. [31] reported that blood eosinophil levels in patients were directly correlated with sinus mucosal thickening and associated with osteitis. Gunel et al. [32] reported that high levels of P-glycoprotein (P-gp) were linked with an increased osteitis burden as measured by the Kennedy Osteitis Score and the GOSS. P-gp, also referred to as multidrug resistance protein, functions as an adenosine triphosphate-dependent efflux pump and is expressed in a variety of cell types, including both immune cells and epithelial cells. Patients with CRSwNP and eosinophilic CRSsNP had higher expression levels of P-gp in nasal mucosa than healthy controls [33-35]. It was demonstrated that P-gp exhibited immunomodulatory activity and affected the secretion of inflammatory cytokines and chemokines [36]. Bleier et al. [37] docu- 
mented that P-gp directly promoted Th2-associated cytokine secretion into the local tissue microenvironment. Thus, the strong association of eosinophils with osteitic bone may provide a compelling explanation for new bone formation in CRS patients. The ability of eosinophils to secrete various proinflammatory mediators suggests that these cells have the possibility to directly impact osteogenic cells [38-40].

\section{The role of cytokines and growth factors}

Tuszynska et al. [41] found a significant upregulation of interleukin (IL)-6, IL-11, and tumor necrosis factor (TNF)- $\alpha$ expression levels in CRS patients with osteitis. Wang et al. [42] explored the significance of transforming growth factor (TGF)- $\beta$ /Smad signaling in osteitis in CRS with and without nasal polyps. Gunel et al. [43] evaluated tissue samples obtained from osteitic bone and the overlying mucosa in CRSsNP patients and healthy controls ( $n=8$ per group). They found that growth differentiation factor (GDF)-5 and exostosin glycosyltransferase 1 were significantly upregulated and positively correlated with mucosal eosinophilic inflammation in CRS patients with osteitis. In addition, a correlation was found between mucosal eosinophil count and GDF-5 levels. Those findings suggest that eosinophilic inflammation may trigger bony changes via GDF-5. GDF-5 is a member of the bone morphogenetic protein (BMP) family, which belongs to the TGF- $\beta$ superfamily and plays a critical role in bone formation [44]. Some members of the BMP family were shown to be upregulated or downregulated in a mouse model of eosinophilic CRS [45]. However, little is known regarding the specific role of BMP family members in CRS patients with osteitis.

In a more recent study, Wu et al. [46] assessed mucosal samples obtained from sites of osteitic bone in 10 patients with CRSwNP and 10 healthy controls. The authors found that pro-osteoblastic expression of BMP-7, BMP-9, and their receptors (BMPR1A and BMPR2) were downregulated in CRSwNP, indicating a generalized decrease in pro-osteoblastic activity. Furthermore, downregulated BMP signaling was significantly associated with increased osteitis in CRSwNP.

Recently, Oue et al. [47] evaluated sinonasal bone and mucosa samples from 38 patients with CRS with and without neo-osteogenesis and nine control patients. In their study, the expression of IL-13, CCL13, colony-stimulating factor 3, integrin alpha $\mathrm{M}$, alkaline phosphatase liver/bone/kidney, and TNF- $\alpha$ were significantly upregulated in CRS patients with neo-osteogenesis when compared with control patients and CRS patients without neo-osteogenesis. Moreover, a significant positive correlation was found between GOSS scores and IL-13 mRNA levels. A positive correlation was found between IL-13 concentrations and the degree of mineralization in primary osteoblasts isolated from CRS patients. Silfversward et al. [40] showed that IL-4 and IL-13 enhanced markers of differentiated osteoblastic activity, including stimulation of collagen secretion, alkaline phosphatase expression, and mineralization. Furthermore, the expression of
IL-13 presented a significant positive correlation with osteogenesis-related gene sets in the human CRS transcriptome [48]. Shi et al. [49] demonstrated that IL-13 promoted the expression of runt-related transcription factor 2 (RUNX2) in human bronchial epithelial cells. Moreover, elevated levels of IL-13 and IL-17A in CRS patients with neo-osteogenesis were found to be related to osteoblast differentiation through the induction of RUNX2 [50]. RUNX2, also known as core-binding factor subunit alpha-1, is an essential transcription factor for osteoblast development and differentiation [51]. It acts throughout the induction, proliferation, and maturation of osteoblasts and regulates the expression of many osteoblast genes [52,53]. RUNX2 expression was detected in cells around new bone surfaces in CRS sinonasal specimens, and a significant positive correlation was found between GOSS scores and RUNX2-positive cells [50].

\section{The role of the RANKL/RANK/OPG axis}

The differentiation of bone-resorbing cells is centered on the key osteoclastogenic cytokine receptor activator of nuclear factor- $\mathrm{kB}$ ligand (RANKL; also known as TNF ligand superfamily member 11). RANKL has two receptors, a signaling receptor (RANK) and a decoy receptor (osteoprotegerin [OPG]); both belong to the TNF superfamily [54,55]. Various studies have demonstrated that RANKL is mainly produced by T cells, B cells, and basophils [56-58]. Kong et al. [25] assessed mucosal samples from 71 patients with CRS and 12 healthy subjects to investigate the expression of RANKL and analyzed the correlation between RANKL expression and osteitis. RANKL expression was upregulated in patients with CRS and was associated with clinical osteitis and disease severity. Immunohistochemical staining showed that RANKL-positive cells were significantly more densely distributed in the periosteum of CRS tissue than in control tissue. Multiple inflammatory mediators were also positively correlated with RANKL protein expression. Furthermore, RANKL/OPG expression was found to be higher in recurrent cases than in primary cases, showing that RANKL is related to osteitis in cases of CRS with a poor prognosis. In contrast, OPG protein expression was lower in recurrent cases than in primary cases.

Bone is a highly dynamic tissue that is remodeled in response to diverse inflammatory stimuli (Fig. 1). More studies are needed to elucidate the impact of proinflammatory cytokines and growth factors produced by immune cells on bone biology. A thorough confirmation and complete understanding of the role that immune cells play in bone remodeling in CRS are essential to facilitate the ongoing search for improved therapeutics.

\section{ROLE OF BACTERIA IN OSTEITIS}

To date, few studies have reported the role played by bacteria in osteitis. Huang et al. [59] performed a retrospective study to evaluate predictive factors of neo-osteogenesis in CRS. The main fo- 


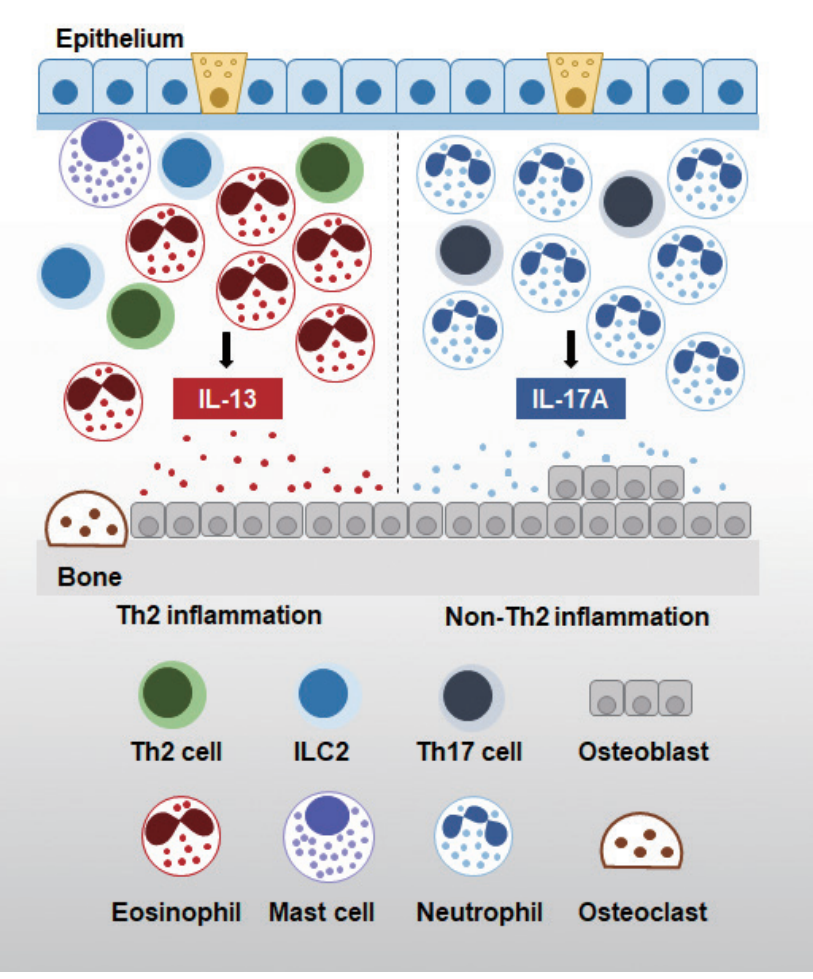

Fig. 1. The interplay between immune cells and bone in chronic rhinosinusitis (CRS). Immune cells are involved in shaping the CRS pathophysiology and directly impact osteogenic cells. IL-13 is a pleiotropic type 2 cytokine that contributes to bone remodeling in patients with eosinophilic CRS through its effects on the activity of osteoblasts. IL-17A is a cytokine secreted primarily by Th17 cells that regulates the activity of osteoblasts in non-eosinophilic CRS. IL, interleukin; Th, T helper; ILC2, type 2 innate lymphoid cells.

cus of that study was the evaluation of bacterial cultures in these groups, which revealed that the presence of Pseudomonas aeruginosa was strongly predictive of neo-osteogenesis. In contrast, the presence of Staphylococcus aureus and coagulase-negative $S$. aureus in the sinuses was not associated with development of neo-osteogenesis. That study was the first to demonstrate that bacteriological factors predicted neo-osteogenesis. In agreement with previous studies, Huang et al. [59] also demonstrated that prior surgery and Lund-Mackay scores were independent predictors of neo-osteogenesis. In a more recent study, Karempelis et al. [60] found that the presence of P. aeruginosa was not associated with neo-osteogenesis in CRS patients with or without cystic fibrosis. That result is in contrast to a previous report. In agreement with a prior study, neither $S$. aureus nor coagulasenegative $S$. aureus affected neo-osteogenesis in patients with CRS.

Dong et al. [61] investigated the association between bacterial biofilms and osteitis status in CRS patients. In their study, $84.8 \%$ of the bones underlying mucosa with biofilms had histopathologic and radiologic evidence of osteitis. Furthermore, the CRS patients who had previously undergone surgery had significantly higher bacterial biofilm and osteitis scores than patients undergoing primary surgery. However, the specific role of bacterial biofilms in the pathogenesis of CRS with osteitis has yet to be revealed [62].

\section{APPLICATIONS OF ANIMAL MODELS FOR ELUCIDATING MOLECULAR MECHANISMS ANDTESTING NOVEL THERAPEUTIC CANDIDATES}

Animal models have strongly contributed to the explanation of mechanisms involved in CRS pathophysiology and the development of novel therapies [63-65]. Rabbit models have been used to elucidate bony changes in CRS in several studies. Perloff et al. [66] identified the histological changes that occurred in bone and in the overlying mucosa in an experimentally induced CRS model. Khalid et al. [67] showed that rabbits inoculated with bacterial organisms (P. aeruginosa and S. aureus) developed chronic sinusitis and had evidence of osteomyelitis. Clear evidence was found of an inflammatory reaction associated with fibrosis, periosteal reaction, hyperplastic osteoblasts, osteoclastic resorption, and Haversian canal changes. Similarly, Dong et al. [68] evaluated bone remodeling at 4,8 , and 12 weeks after intranasal inoculation of $S$. aureus. The presence of osteitis was identified by changes in periosteal thickening, osteoblastic and osteoclastic activity, and woven bone formation in sections used for histologic scoring.

Murine models have been used to study the pathophysiology of CRS in several recent studies [69-75]. Mice have several advantages over rabbits as a model of CRS, including the availability of reagents to explore immunological responses and the availability of many knockout and transgenic models. Other advantages of the mouse model include the small size of mice, which significantly reduces the amounts of drugs or chemicals needed for experiments [76,77]. In a recent study, our research group [48] found histologic and radiographic evidence of new bone formation or neo-osteogenesis in an eosinophilic CRS model and explored the relationship between IL-13 and RUNX2. In that study, RUNX2-immunoreactive osteoblasts were significantly increased and positively correlated with bone thickness and IL-13 expression in experimental mice. Furthermore, the administration of resveratrol (known to be a SIRT1 activator) reduced mucosal inflammation $[78,79]$ and new bone formation, suggesting the applicability of this murine model for investigating the efficiency of drugs targeting CRS patients with neo-osteogenesis. In a recent study, Kong et al. [25] showed that anti-RANKL treatment inhibited mucosal inflammation and related osteitis in a murine model of CRS. Thus, this murine model can be used to elucidate the mechanism of new bone formation in CRS and might open new avenues towards the identification of novel therapeutic strategies. 


\section{CONCLUSION}

Osteitis is associated with severe mucosal inflammation and revision sinus surgery, but its role in CRS pathophysiology remains poorly understood. Immune cells play a critical role in bone remodeling in CRS patients. Therefore, a detailed knowledge of the involvement of the immune system, and the cytokines and immune signals that mediate bone biology in CRS, will contribute significantly to drug development.

\section{CONFLICT OF INTEREST}

Hyun Woo Shin is an editorial board member of the journal but did not involve in the peer reviewer selection, evaluation, or decision process of this article. No other potential conflicts of interest relevant to this article were reported.

\section{ACKNOWLEDGMENTS}

This work was supported by a grant from the National Research Foundation of Korea (2020R1A4A2002903) and the Education and Research Encouragement Fund of Seoul National University Hospital (2020).

\section{ORCID}

Roza Khalmuratova https://orcid.org/0000-0002-8518-4034

Hyun-Woo Shin ～https://orcid.org/0000-0002-4038-9992

\section{AUTHOR CONTRIBUTIONS}

Conceptualization: all authors. Funding acquisition: HWS. Project administration: HWS. Visualization: RK. Writing-original draft: RK.Writing-review \& editing: HWS.

\section{REFERENCES}

1. Fokkens WJ, LundVJ, Mullol J, Bachert C,Alobid I, Baroody F, et al. EPOS 2012: European position paper on rhinosinusitis and nasal polyps 2012. A summary for otorhinolaryngologists. Rhinology. 2012 Mar;50(1):1-12.

2. Hamilos DL. Chronic rhinosinusitis: epidemiology and medical management. J Allergy Clin Immunol. 2011 Oct;128(4):693-707.

3. Schleimer RP. Immunopathogenesis of chronic rhinosinusitis and nasal polyposis. Annu Rev Pathol. 2017 Jan;12:331-57.

4. Khalmuratova R, Park JW, Shin HW. Immune cell responses and mucosal barrier disruptions in chronic rhinosinusitis. Immune Netw. 2017 Feb;17(1):60-7.

5. Akdis CA, Bachert C, Cingi C, Dykewicz MS, Hellings PW, Naclerio
RM, et al. Endotypes and phenotypes of chronic rhinosinusitis: a PRACTALL document of the European Academy of Allergy and Clinical Immunology and the American Academy of Allergy, Asthma \& Immunology. J Allergy Clin Immunol. 2013 Jun;131(6):1479-90.

6. Van ZeleT, Claeys S, Gevaert P,Van Maele G, Holtappels G, Van Cauwenberge $\mathrm{P}$, et al. Differentiation of chronic sinus diseases by measurement of inflammatory mediators. Allergy. 2006 Nov;61(11): 1280-9.

7. Brescia G, Zanotti C, Parrino D, Barion U, Marioni G. Nasal polyposis pathophysiology: endotype and phenotype open issues. Am J Otolaryngol. 2018 Jul-Aug;39(4):441-4.

8. Cao PP, Li HB, Wang BF, Wang SB, You XJ, Cui YH, et al. Distinct immunopathologic characteristics of various types of chronic rhinosinusitis in adult Chinese. J Allergy Clin Immunol. 2009 Sep;124(3): 478-84.

9. Kim SJ, Lee KH, Kim SW, Cho JS, Park YK, Shin SY. Changes in histological features of nasal polyps in a Korean population over a 17year period. Otolaryngol Head Neck Surg. 2013 Sep;149(3):431-7.

10. Tikaram A, Prepageran N.Asian nasal polyps: a separate entity? Med J Malaysia. 2013 Dec;68(6):445-7.

11. Cho SW, Kim DW, Kim JW, Lee CH, Rhee CS. Classification of chronic rhinosinusitis according to a nasal polyp and tissue eosinophilia: limitation of current classification system for Asian population. Asia Pac Allergy. 2017 Jul;7(3):121-30.

12. Snidvongs K, Sacks R, Harvey RJ. Osteitis in chronic rhinosinusitis. Curr Allergy Asthma Rep. 2019 Mar;19(5):24.

13. Bhandarkar ND, Sautter NB, Kennedy DW, Smith TL. Osteitis in chronic rhinosinusitis: a review of the literature. Int Forum Allergy Rhinol. 2013 May;3(5):355-63.

14. Snidvongs K, Earls P, Dalgorf D, Sacks R, Pratt E, Harvey RJ. Osteitis is a misnomer: a histopathology study in primary chronic rhinosinusitis. Int Forum Allergy Rhinol. 2014 May;4(5):390-6.

15. Lee JT, Kennedy DW, Palmer JN, Feldman M, Chiu AG. The incidence of concurrent osteitis in patients with chronic rhinosinusitis: a clinicopathological study. Am J Rhinol. 2006 May-Jun;20(3):278-82.

16. Sacks PL, Snidvongs K, Rom D, Earls P, Sacks R, Harvey RJ.The impact of neo-osteogenesis on disease control in chronic rhinosinusitis after primary surgery. Int Forum Allergy Rhinol. 2013 Oct;3(10): 823-7.

17. Snidvongs K, McLachlan R, Chin D, Pratt E, Sacks R, Earls P, et al. Osteitic bone: a surrogate marker of eosinophilia in chronic rhinosinusitis. Rhinology. 2012 Sep;50(3):299-305.

18. Georgalas C,VidelerW, Freling N, FokkensW. Global Osteitis Scoring Scale and chronic rhinosinusitis: a marker of revision surgery. Clin Otolaryngol. 2010 Dec;35(6):455-61.

19. Cho SH, Min HJ, Han HX, Paik SS, Kim KR. CT analysis and histopathology of bone remodeling in patients with chronic rhinosinusitis. Otolaryngol Head Neck Surg. 2006 Sep;135(3):404-8.

20. Biedlingmaier JF, Whelan P, Zoarski G, Rothman M. Histopathology and CT analysis of partially resected middle turbinates. Laryngoscope. 1996 Jan;106(1 Pt 1):102-4.

21. Giacchi RJ, Lebowitz RA, Yee HT, Light JP, Jacobs JB. Histopathologic evaluation of the ethmoid bone in chronic sinusitis. Am J Rhinol. 2001 May-Jun;15(3):193-7.

22. Bhandarkar ND, Mace JC, Smith TL. The impact of osteitis on disease severity measures and quality of life outcomes in chronic rhinosinusitis. Int Forum Allergy Rhinol. 2011 Sep-Oct;1(5):372-8.

23. Snidvongs K, McLachlan R, Sacks R, Earls P, Harvey RJ. Correlation of the Kennedy Osteitis Score to clinico-histologic features of chronic rhinosinusitis. Int Forum Allergy Rhinol. 2013 May;3(5):369-75.

24. Meng Y, Lou H, Wang C, Zhang L. Predictive significance of computed tomography in eosinophilic chronic rhinosinusitis with nasal polyps. Int Forum Allergy Rhinol. 2016 Aug;6(8):812-9.

25. Kong IG, Kim DK, Eun KM, Yang SK, Kim M, Oh H, et al. Receptor 
activator of nuclear factor $\mathrm{\kappa B}$ ligand is a biomarker for osteitis of chronic rhinosinusitis. Int Forum Allergy Rhinol. 2020 Mar;10(3): 364-73.

26. Florencio-Silva R, Sasso GR, Sasso-Cerri E, Simoes MJ, Cerri PS. Biology of bone tissue: structure, function, and factors that influence bone cells. Biomed Res Int. 2015;2015:421746.

27. Caetano-Lopes J, Canhao H, Fonseca JE. Osteoblasts and bone formation. Acta Reumatol Port. 2007 Apr-Jun;32(2):103-10.

28. Metzger CE, Narayanan SA. The role of osteocytes in inflammatory bone loss. Front Endocrinol (Lausanne). 2019 May;10:285.

29. Ishino T, Yajin K, Takeno S, Furukido K, Hirakawa K. Establishment of osteoblast culture from human ethmoidal sinus. Auris Nasus Larynx. $2003 \mathrm{Feb} ; 30(1): 45-51$.

30. Stevens PR, Tessema B, Brown SM, Parham K, Gronowicz G. Chronic rhinosinusitis osteoblasts differ in cellular properties from normal bone. Int Forum Allergy Rhinol. 2015 Feb;5(2):124-31.

31. MehtaV, Campeau NG, Kita H, Hagan JB. Blood and sputum eosinophil levels in asthma and their relationship to sinus computed tomographic findings. Mayo Clin Proc. 2008 Jun;83(6):671-8.

32. Gunel C, Feldman RE, Bleier BS. Osteitis is associated with P-glycoprotein overexpression in patients with chronic sinusitis without nasal polyps. Am J Rhinol Allergy. 2014 Mar-Apr;28(2):99-102.

33. Miyake MM, Nocera A, Miyake MM. P-glycoprotein and chronic rhinosinusitis. World J Otorhinolaryngol Head Neck Surg. 2018 Aug; 4(3):169-74.

34. Cheng YS, Bleier BS. Influence of P-glycoprotein function on chronic rhinosinusitis/nasal polyps pathophysiology. Adv Otorhinolaryngol. 2016;79:38-47.

35. Feldman RE, Lam AC, Sadow PM, Bleier BS. P-glycoprotein is a marker of tissue eosinophilia and radiographic inflammation in chronic rhinosinusitis without nasal polyps. Int Forum Allergy Rhinol. 2013 Aug;3(8):684-7.

36. Bleier BS, Nocera AL, Iqbal H, Hoang JD, Alvarez U, Feldman RE, et al. P-glycoprotein promotes epithelial T helper 2-associated cytokine secretion in chronic sinusitis with nasal polyps. Int Forum Allergy Rhinol. 2014 Jun;4(6):488-94.

37. Bleier BS, Singleton A, Nocera AL, Kocharyan A, Petkova V, Han X. P-glycoprotein regulates Staphylococcus aureus enterotoxin B-stimulated interleukin-5 and thymic stromal lymphopoietin secretion in organotypic mucosal explants. Int Forum Allergy Rhinol. 2016 Feb; 6(2):169-77.

38. Onoe Y, Miyaura C, Kaminakayashiki T, Nagai Y, Noguchi K, Chen QR, et al. IL-13 and IL-4 inhibit bone resorption by suppressing cyclooxygenase-2-dependent prostaglandin synthesis in osteoblasts. J Immunol. 1996 Jan;156(2):758-64.

39. Silfversward CJ, Larsson S, Ohlsson C, Frost A, Nilsson O. Reduced cortical bone mass in mice with inactivation of interleukin- 4 and interleukin-13. J Orthop Res. 2007 Jun;25(6):725-31.

40. Silfversward CJ, Penno H, Frost A, Nilsson O, Ljunggren O. Expression of markers of activity in cultured human osteoblasts: effects of interleukin-4 and interleukin-13. Scand J Clin Lab Invest. 2010 Sep; 70(5):338-42.

41. Tuszynska A, Krzeski A, Postuba M, Paczek L, Wyczalkowska-Tomasik A, Gornicka B, et al. Inflammatory cytokines gene expression in bone tissue from patients with chronic rhinosinusitis: a preliminary study. Rhinology. 2010 Dec;48(4):415-9.

42. Wang M, Ye T, Liang N, Huang Z, Cui S, LiY, et al. Differing roles for TGF- $\beta /$ Smad signaling in osteitis in chronic rhinosinusitis with and without nasal polyps. Am J Rhinol Allergy. 2015 Sep-Oct;29(5): e152-9.

43. Gunel C, Bleier BS, Bozkurt G, Eliyatkin N. Microarray analysis of the genes associated with osteitis in chronic rhinosinusitis. Laryngoscope. 2017 Mar;127(3):E85-90.

44. Jin L, Li X. Growth differentiation factor 5 regulation in bone regen- eration. Curr Pharm Des. 2013;19(19):3364-73.

45. Sautter NB, Delaney KL, Hausman FA, Trune DR. Tissue remodeling gene expression in a murine model of chronic rhinosinusitis. Laryngoscope. 2012 Apr;122(4):711-7.

46. Wu D, Nocera AL, Mueller SK, Finn K, Libermann TA, Bleier BS. Osteitis is associated with dysregulated pro-osteoblastic activity in patients with nasal polyps. Laryngoscope. 2019 Mar;129(3):E102-9.

47. Oue S, Ramezanpour M, Paramasivan S, Miljkovic D, Cooksley CM, Bassiouni A, et al. Increased IL-13 expression is independently associated with neo-osteogenesis in patients with chronic rhinosinusitis. J Allergy Clin Immunol. 2017 Nov;140(5):1444-8.

48. Khalmuratova R, Lee M, Park JW, Shin HW. Evaluation of neo-osteogenesis in eosinophilic chronic rhinosinusitis using a nasal polyp murine model.Allergy Asthma Immunol Res. 2020 Mar;12(2):306-21.

49. Shi N, Zhang J, Chen SY. Runx2, a novel regulator for goblet cell differentiation and asthma development. FASEB J. 2017 Jan;31(1): 412-20.

50. Khalmuratova R, Shin HW, Kim DW, Park JW. Interleukin (IL)-13 and IL-17A contribute to neo-osteogenesis in chronic rhinosinusitis by inducing RUNX2. EBioMedicine. 2019 Aug;46:330-41.

51. Komori T. Regulation of bone development and maintenance by Runx2. Front Biosci. 2008 Jan;13:898-903.

52. Jensen ED, Gopalakrishnan R, Westendorf JJ. Regulation of gene expression in osteoblasts. Biofactors. 2010 Jan-Feb;36(1):25-32.

53. KomoriT. Regulation of bone development and extracellular matrix protein genes by RUNX2. Cell Tissue Res. 2010 Jan;339(1):189-95.

54. Boyce BF, Xing L. Functions of RANKL/RANK/OPG in bone modeling and remodeling. Arch Biochem Biophys. 2008 May;473(2): 139-46.

55. Walsh MC, Choi Y. Biology of the RANKL-RANK-OPG system in immunity, bone, and beyond. Front Immunol. 2014 Oct;5:511.

56. Yeo L, Toellner KM, Salmon M, Filer A, Buckley CD, Raza K, et al. Cytokine mRNA profiling identifies B cells as a major source of RANKL in rheumatoid arthritis. Ann Rheum Dis. 2011 Nov;70(11): 2022-8.

57. Ogasawara N, Poposki JA, Klingler AI, Tan BK, Hulse KE, Stevens WW, et al. Role of RANK-L as a potential inducer of ILC2-mediated type 2 inflammation in chronic rhinosinusitis with nasal polyps. Mucosal Immunol. 2020 Jan;13(1):86-95.

58. Huber C, Odermatt A, Hagmann B, Dahinden CA, Fux M. In human basophils, IL-3 selectively induces RANKL expression that is modulated by IgER-dependent and IgER-independent stimuli. Allergy. 2014 Nov;69(11):1498-505.

59. Huang Z, Hajjij A, Li G, Nayak JV, Zhou B, Hwang PH. Clinical predictors of neo-osteogenesis in patients with chronic rhinosinusitis. Int Forum Allergy Rhinol. 2015 Apr;5(4):303-9.

60. Karempelis P, Karp E, Rubin N, Hunter R, Dunitz J, Boyer H. Risk factors for neo-osteogenesis in cystic fibrosis and non-cystic fibrosis chronic rhinosinusitis. Int Forum Allergy Rhinol. 2020 Apr;10(4): 505-10.

61. Dong D, Yulin Z, Xiao W, Hongyan Z, Jia L, Yan X, et al. Correlation between bacterial biofilms and osteitis in patients with chronic rhinosinusitis. Laryngoscope. 2014 May;124(5):1071-7.

62. Zhao YC, Wormald PJ. Biofilm and osteitis in refractory chronic rhinosinusitis. Otolaryngol Clin North Am. 2017 Feb;50(1):49-60.

63. Braga AA, Valera FC, Faria FM, Rossato M, Murashima AA, Fantucci MZ, et al. An experimental model of eosinophilic chronic rhinosinusitis induced by bacterial toxins in rabbits. Am J Rhinol Allergy. 2019 Nov;33(6):737-50.

64. Cho DY, Mackey C, Van Der PolWJ, Skinner D, Morrow CD, Schoeb TR, et al. Sinus microanatomy and microbiota in a rabbit model of rhinosinusitis. Front Cell Infect Microbiol. 2018 Jan;7:540.

65. Shin HW. Animal models in CRS and pathophysiologic insights gained: a systematic review. Laryngoscope Investig Otolaryngol. 
2016 Aug; 1(5):116-23.

66. Perloff JR, Gannon FH, BolgerWE, Montone KT, Orlandi R, Kennedy DW. Bone involvement in sinusitis: an apparent pathway for the spread of disease. Laryngoscope. 2000 Dec;110(12):2095-9.

67. Khalid AN, Hunt J, Perloff JR, Kennedy DW. The role of bone in chronic rhinosinusitis. Laryngoscope. 2002 Nov;112(11):1951-7.

68. Dong Y, Zhou B, Wang X, Huang Z, Wang M, Li Y, et al. Computed tomography and histopathological evaluation of osteitis in rabbit models with rhinosinusitis. Acta Otolaryngol. 2017 May;137(5): 534-40.

69. Khalmuratova R, Lee M, Kim DW, Park JW, Shin HW. Induction of nasal polyps using house dust mite and Staphylococcal enterotoxin B in C57BL/6 mice. Allergol Immunopathol (Madr). 2016 Jan-Feb; 44(1):66-75.

70. Kim DW, Khalmuratova R, Hur DG, Jeon SY, Kim SW, Shin HW, et al. Staphylococcus aureus enterotoxin B contributes to induction of nasal polypoid lesions in an allergic rhinosinusitis murine model. Am J Rhinol Allergy. 2011 Nov-Dec;25(6):e255-61.

71. Wang S, Zhang H, Xi Z, Huang J, Nie J, Zhou B, et al. Establishment of a mouse model of lipopolysaccharide-induced neutrophilic nasal polyps. Exp Ther Med. 2017 Dec;14(6):5275-82.

72. Lee M, Kim DW, Yoon H, So D, Khalmuratova R, Rhee CS, et al. Sirtuin 1 attenuates nasal polypogenesis by suppressing epithelial-tomesenchymal transition. J Allergy Clin Immunol. 2016 Jan;137(1): 87-98.
73. Lee M, Park CG, Huh BK, Kim SN, Lee SH, Khalmuratova R, et al. Sinonasal delivery of resveratrol via mucoadhesive nanostructured microparticles in a nasal polyp mouse model. Sci Rep. 2017 Jan;7: 40249.

74. Kim SW, Kim JH, Jung MH, Hur DG, Lee HK, Jeon SY, et al. Periostin may play a protective role in the development of eosinophilic chronic rhinosinusitis with nasal polyps in a mouse model. Laryngoscope. 2013 May;123(5):1075-81.

75. Khalmuratova R, Lee M, Mo JH, Jung Y, Park JW, Shin HW.Wogonin attenuates nasal polyp formation by inducing eosinophil apoptosis through HIF-1 $\alpha$ and survivin suppression. Sci Rep. 2018 Apr;8(1): 6201.

76. VandammeTF. Rodent models for human diseases. Eur J Pharmacol. 2015 Jul;759:84-9.

77. Wang Z, Chang L, Huang J, Huang Z, Li X, Chen X, et al. Histologi$\mathrm{cal}$ and computed tomographic characteristics of the sinonasal structure of BALB/c mice. Anat Histol Embryol. 2020 Mar;49(2):222-6.

78. Kim SW, Kim DW, Khalmuratova R, Kim JH, Jung MH, Chang DY, et al. Resveratrol prevents development of eosinophilic rhinosinusitis with nasal polyps in a mouse model. Allergy. 2013 Jul;68(7):862-9.

79. Kim Y, Hwang S, Khalmuratova R, Kang S, Lee M, Song Y, et al. $\alpha$-Helical cell-penetrating peptide-mediated nasal delivery of resveratrol for inhibition of epithelial-to-mesenchymal transition. J Control Release. 2020 Jan;317:181-94. 